\title{
DEZ ANOS DE REVISTA DIÁLOGO EDUCACIONAL (2000-2009): histórico e evolução
}

\section{Ten years of Journal Diálogo Educacional (2000-2009): historical and evolution}

\section{Leilah Santiago Bufrem ${ }^{[a]}$, Rene Faustino Gabriel Junior ${ }^{[b]}$, Viviane Gonçalves ${ }^{[\mathrm{c}]}$}

[a] Doutora em Ciências da Comunicação pela Universidade de São Paulo (USP), PósDoutora pela Universidad Autónoma de Madrid, professora titular do departamento de Ciência, Gestão e Tecnologia da Informação da Universidade Federal do Paraná (UFPR), Curitiba, PR - Brasil, e-mail:1eilah@ufpr.br

${ }^{[b]}$ Mestrando em Ciência, Gestão e Tecnologia da Informação, Universidade Federal do Paraná (UFPR), Curitiba, PR - Brasil, e-mail: rene@sisdoc.com.br

${ }^{[c]}$ Mestranda em Ciência, Gestão e Tecnologia da Informação, Universidade Federal do Paraná(UFPR), Curitiba, PR - Brasil, e-mail: viviane@sisdoc.com.br

\section{Resumo}

O papel desempenhado pelas revistas científicas para divulgação dos resultados de pesquisas e novas descobertas tem contribuído para a consolidação da ciência como difusora do conhecimento científico.

Rev. Diálogo Educ., Curitiba, v. 10, n. 29, p. 123-149, jan./abr. 2010 
124 BUFREM, L. S.; GABRIEL JUNIOR, R. F.; GONÇALVES, V.

Com o objetivo de analisar diacronicamente os dez anos da Revista Diálogo Educacional, vinculada ao Programa de Pós-Graduação Stricto Sensu em Educação da Pontifícia Universidade Católica do Paraná, este estudo utiliza a técnica de pesquisa biografia institucional. Realiza um levantamento histórico, iniciando com a criação e os marcos do desenvolvimento e consolidação da revista. Demonstra a trajetória desse veículo de comunicação científica voltada ao debate e discussão acerca da área Educação. Apresenta os resultados da análise dos 28 números publicados desde sua criação, em 2000, até 2009 e identifica que a revista já conseguiu alcançar visibilidade nacional, porém sua consolidação na área ainda depende do aprimoramento de seus critérios de qualidade e da busca do reconhecimento internacional por meio de estratégias constantes de seu planejamento.

Palavras-chave: Periódico científico. Comunicação científica. Educação. Biografia institucional.

\begin{abstract}
The role carried out by the scientific journals for popularization of the results of researchers and new discoveries has been contributing to consolidation of the science of the scientific knowledge. The objective of the article consists of a reflection about the ten years of the Journal Diálogo Educacional linked to the Programa de Pós-Graduação Stricto Sensu in Education of the Pontifícia Universidade Católica do Paraná, using the technique of research institutional biography, which consists of historical rising of creation, development and consolidation. It demonstrates the path of that vehicle of scientific communication returned to the debate and discussion concerned about Education. To presents the results of the analysis of the 28 numbers published from your creation of 2000-2009 and it identifies that the journal already got to reach national visibility, however the road to be conquered for your consolidation in the area which intends it still depends on the your quality criteria and the search of the international recognition through strategies that will be traced next years.
\end{abstract}

Keywords: Scientific journal. Scientific communication. Education. Institution biography.

Rev. Diálogo Educ., Curitiba, v. 10, n. 29, p. 123-149, jan./abr. 2010 


\section{INTRODUÇÃO}

O desenvolvimento da ciência consolida-se por meio da pesquisa e proporciona ao pesquisador reconhecimento por seus pares. Sendo assim, para a efetivação da ciência, é necessário que ela seja comunicada. No processo de difusão do conhecimento, as revistas científicas tornam-se o canal para disseminação de novas descobertas, divulgando a outros pesquisadores e à comunidade científica os resultados obtidos e, desse modo, contribuindo para a ciência formal.

O periódico científico ou revista científica, denominação cada vez mais aceita para designar as publicações produzidas em intervalos regulares e constituídas graças à contribuição de artigos, é considerado por Stumpf (2003) como um dos produtos da ciência que tem tido maior aceitação como registro da produção científica.

O reconhecimento pela comunidade científica exige do pesquisador a publicação de suas pesquisas e, para esse fim, cada vez mais se impõe a busca pelas revistas mais bem avaliadas pelos órgãos reguladores e indexadores, para então ocorrer a submissão do artigo. É certo, porém, que quanto melhor a avaliação da revista, maior é o interesse dos mais renomados pesquisadores nela publicarem, o que dificulta, consequentemente, a participação de novos autores nessas publicações, principalmente dada a quantidade reduzida de artigos publicados em cada edição.

Do outro lado do processo da comunicação científica, podese identificar o papel desempenhado pelo editor-chefe da revista, o responsável pelo recebimento das submissões dos pesquisadores, escolha e envio a pareceristas da área para avaliação (blind review) e finalmente para decidir o que pode ser publicado e em qual edição.

Consolidando-se na área de Educação, a Revista Diálogo Educacionalé um dos periódicos científicos que se propõe a disponibilizar informações científicas de qualidade para a comunidade da área. Como resposta ao mérito do trabalho desempenhado por seus editores-chefe e equipe de apoio, a Revista Diálogo Educacional, no ano de 2007, obteve seu valor reconhecido pela Coordenação de Aperfeiçoamento de Pessoal de Nivel Superior (CAPES) recebendo avaliação B1 pela sua contribuição na área de educação, contando com reconhecimento nacional.

Com base no histórico da revista, o objetivo do presente artigo é apresentar, utilizando a técnica de pesquisa biografia institucional, a

Rev. Diálogo Educ., Curitiba, v. 10, n. 29, p. 123-149, jan./abr. 2010 
trajetória da Revista Diálogo Educacional, analisando seus momentos de criação e principais realizações, sob uma perspectiva diacrônica, para ressaltar que a continuidade de seu desenvolvimento envolve projetos para que se torne uma revista internacionalmente relevante para a área por meio do constante aprimoramento de seus critérios de qualidade. Para análise dos resultados, foram avaliados os 28 números da Revista Diálogo Educacional, publicados entre 2000 e 2009, utilizando-se a metodologia Brapci ${ }^{1}$, que possibilitou identificar as relações e dados estatísticos dos autores e de instituições que contribuíram com a revista ao longo desses dez anos.

\section{Marcos da comunicação científica}

Os primórdios da comunicação científica, de acordo com Meadows (1999), devem-se aos gregos antigos por causa de sua pesquisa científica falada e escrita. As discussões científicas remontam à Academia, o lugar na periferia de Atenas onde as pessoas se reuniam nos séculos VI e V a.C. para debater questões filosóficas.

Segundo Meadows (1999, p. vii), "a comunicação situa-se no próprio coração da ciência. É para ela tão vital quanto a própria pesquisa, pois a esta não cabe reivindicar com legitimidade este nome enquanto não houver sido analisada e aceita pelos pares. Isto exige necessariamente que ela seja comunicada".

O advento da revista científica data do século XVII, com o surgimento do Journal des Sçavants, fundado pelo francês Denis de Sallo (MEADOWS, 1999). A comunicação de novas descobertas científicas era realizada anteriormente por um grupo restrito de pesquisadores que trocavam cartas para divulgar suas ideias ou esporadicamente se reuniam para trocar conhecimento.

O cerne da concretização da revolução científica ficou evidenciado com a invenção da imprensa no século $\mathrm{XV}$, fato que exerceu importante papel na difusão do conhecimento científico. De acordo com Price (1976, p. 145), tanto o periódico científico quanto o artigo representam "uma das inovações mais características e notáveis da revolução científica”. Para Stumpf (2003), é o meio mais apropriado

Projeto financiado pelo CNPq para desenvolvimento de metodologia de construção de uma base de dados referencial de periódicos científicos na área de Ciência da Informação.

Rev. Diálogo Educ., Curitiba, v. 10, n. 29, p. 123-149, jan./abr. 2010 
para comunicar o resultado de novas descobertas e observações originais para a comunidade científica de referência, assegurando ao autor a prioridade da descoberta, de ideia ou da interpretação.

O periódico científico demonstra sua importância quando nos remete a autoridade do que é escrever e do grande valor que esse ato representa, pois a linguagem escrita é uma das conquistas mais relevantes da humanidade, ela passa a ter importância quando é descoberta e reconhecida como uma forma de comunicação. A explicitação permite que a informação seja socializada (BOARINI, 2003).

Assim, ao serem publicadas, as revistas cumprem práticas de um itinerário consagrador, definido pelas relações presentes no âmbito da sua área de atuação, de modo a assegurar, tanto seu retorno econômico quanto simbólico, pois o contexto comporta a existência de grupos em formação e até em competição, ocupantes de diversas posições no que Bourdieu (1987), consideraria um campo da produção cultural todos em busca da legitimidade atribuída pelas instâncias de consagração.

A partir da década de 1950, um grande número de periódicos científicos começou a surgir, principalmente nos Estados Unidos e Europa, contribuindo para o rápido crescimento das inovações. Nessa mesma época, Eugene Garfield, cujo primeiro trabalho data de 1955, demonstrou preocupação em identificar, entre a grande quantidade de títulos existentes, quais seriam os mais importantes para cada área, o que ele chamou de literatura nuclear, para estabelecer pelo fator de impacto, o núcleo básico de publicações relevantes na área.

Em 1972, o Journal Citation Report (JCR) começou a utilizar índices bibliométricos que geravam o fator de impacto. A utilização desse indicador é considerada uma importante ferramenta para avaliação das publicações, especialmente se utilizada na comparação entre títulos de uma mesma área do conhecimento.

\section{Critérios de qualidade em periódicos científicos}

A partir da década de 1960, estudos apontam a preocupação com a avaliação de revistas científicas e técnicas, sinalizando a necessidade de se definirem parâmetros mensuráveis, capazes de refletir a qualidade da informação registrada (KRZYZANOWSKI;

Rev. Diálogo Educ., Curitiba, v. 10, n. 29, p. 123-149, jan./abr. 2010 
FERREIRA, 1998, p. 165). Ainda na visão dessas autoras, várias críticas vêm sendo formuladas, em âmbito internacional, quanto à publicação de revistas "sem critérios de qualidade e para as quais vêm se perdendo esforços, material publicado, recursos financeiros e até prestígio de organizações científicas ou instituições".

Aferir ou mensurar qualidade não é um processo fácil, todavia, quando se trata de revista científica, a avaliação é realizada por um conjunto de aspectos relacionados que, segundo Castro (2008), atendem ao cumprimento das normas estabelecidas pela própria revista, pelo corpo editorial (distribuição geográfica e competência de seus membros), pelo processo de revisão por pares (revisores ou pareceristas e fluxo de revisão), pelo conteúdo e mérito científico (originalidade, relevância e validade), pela regularidade e frequência de publicação, pela aceitação da comunidade científica (distribuição geográfica e citações).

Em geral, esses critérios são analisados por bases de dados e por agências de fomento à pesquisa que são os principais responsáveis pelo controle, medição e análise da produção científica. Para Gonçalves, Ramos e Castro (2006, p. 179) “os motivos pelos quais um editor busca que a revista seja indexada em base de dados estão geralmente ligados à oportunidade de aumento de sua visibilidade e disseminação nacional e/ou internacional".

No Brasil, existe o conjunto de avaliação de procedimentos utilizados pela CAPES para estratificação da qualidade da produção intelectual dos programas de pós-graduação. Tal processo foi concebido para atender às necessidades específicas do sistema de avaliação e é baseado nas informações fornecidas por meio do aplicativo Coleta de Dados. Como resultado, o órgão disponibiliza uma lista com a classificação das revistas publicadas pelos programas de pós-graduação para a divulgação da sua produção, instituída no ano de 1998, com a finalidade de qualificar os periódicos científicos existentes nas áreas (CAPES). Em 2007, o processo de avaliação sofreu modificações e a nova estratificação na Área de Educação (CAPES) passou a ser avaliada de acordo com o Quadro 1.

Rev. Diálogo Educ., Curitiba, v. 10, n. 29, p. 123-149, jan./abr. 2010 
Dez anos de Revista Diálogo Educacional (2000-2009)

QUADRO 1 - Definição dos estratos na área Educação (CAPES)

\begin{tabular}{|c|c|c|c|c|c|c|c|c|}
\hline & & & Estratos & da CAPE & & & & \\
\hline $\begin{array}{l}\text { Itens } \\
\text { avaliados }\end{array}$ & A1 & A2 & B1 & B2 & B3 & B4 & B5 & C \\
\hline ISSN & SIM & SIM & SIM & SIM & SIM & SIM & SIM & SIM \\
\hline Circulação & Internac. & Internac. & Nacional & Nacional & Nacional & Regional & - & - \\
\hline $\begin{array}{l}\text { Reconhecida } \\
\text { pela área }\end{array}$ & SIM & SIM & SIM & SIM & - & - & - & - \\
\hline $\begin{array}{l}\text { Editor } \\
\text { Responsável }\end{array}$ & SIM & SIM & SIM & SIM & SIM & SIM & SIM & SIM \\
\hline $\begin{array}{l}\text { Conselho } \\
\text { Editorial }\end{array}$ & SIM & SIM & SIM & SIM & SIM & SIM & SIM & SIM \\
\hline $\begin{array}{l}\text { Conselho } \\
\text { opcional } \\
\text { Científico }\end{array}$ & SIM & SIM & SIM & SIM & SIM & opcional & opcio & onal \\
\hline $\begin{array}{l}\text { Parecerista } \\
\text { Interinstitucional }\end{array}$ & SIM & SIM & SIM & SIM & SIM & SIM & SIM & SIM \\
\hline $\begin{array}{l}\text { Parecerista } \\
\text { opcional } \\
\text { Internacional }\end{array}$ & SIM & SIM & SIM & NÃO & opcional & opcional & opcior & onal \\
\hline $\begin{array}{l}\text { Periodicidade } \\
\text { mínima }\end{array}$ & Quadr. & Sem. & Sem. & Sem. & Sem. & Sem. & Sem. & - \\
\hline $\begin{array}{l}\text { Artigos } \\
\text { mínimos } \\
\text { por ano }\end{array}$ & 18 & 18 & 14 & 12 & 12 & 12 & 12 & - \\
\hline $\begin{array}{l}\text { Máximo de } \\
\text { autores locais } \\
\text { (artigos) }\end{array}$ & $25 \%$ & $25 \%$ & $40 \%$ & $50 \%$ & $60 \%$ & $60 \%$ & - & - \\
\hline $\begin{array}{l}\text { Artigos } \\
\text { estrangeiros } \\
\text { (mínimo) }\end{array}$ & 2 & 2 & 1 & - & - & - & - & - \\
\hline $\begin{array}{l}\text { Instituições } \\
\text { diferentes }\end{array}$ & 5 & 5 & 4 & 3 & 3 & 3 & - & - \\
\hline $\begin{array}{l}\text { Indexação } \\
\text { Nacional }\end{array}$ & 3 & 3 & - & - & - & - & - & - \\
\hline $\begin{array}{l}\text { Indexação } \\
\text { Internacional }\end{array}$ & 3 & 2 & - & - & - & - & - & - \\
\hline $\begin{array}{l}\text { Indexação } \\
\text { Nacional / } \\
\text { Internacional }\end{array}$ & 6 & 5 & $4^{*}$ & $3 *$ & $2^{*}$ & $1 *$ & - & - \\
\hline
\end{tabular}

* A indexação poder ser nacional ou internacional.

Rev. Diálogo Educ., Curitiba, v. 10, n. 29, p. 123-149, jan./abr. 2010 
A modificação na maneira de avaliação pela CAPES causou grande impacto na comunidade científica, e para a maioria dos periódicos científicos o momento é de reestruturação. O sistema de avaliação CAPES denominado Qualis "costuma gerar polêmicas na comunidade científica e entre os editores, uma vez que os critérios para avaliação das revistas variam em cada área, o que faz com que algumas revistas sejam classificadas em categorias distintas, dependendo da comissão que as avaliou" (GONÇALVES; RAMOS; CASTRO, 2006, p. 183-184).

A avaliação de um periódico contribui igualmente para o comportamento da literatura nas áreas específicas, o que pode ser observado em estudos de autoria e citações. Além disso, a realidade no Brasil aponta para outros fatores que na maioria das vezes não são considerados para avaliação da produção científica das áreas, prejudicando exponencialmente a avaliação e o reconhecimento do periódico científico na comunidade.

\section{METODOLOGIA}

O objetivo deste estudo é apresentar a história dos dez anos da Revista Diálogo Educacional, utilizando a técnica de biografia institucional, a qual consiste em "levantamento histórico de criação, desenvolvimento e consolidação organizacional” (TARAPANOFF, 1995, p. 83).

Entre os motivos para que seja utilizada a biografia institucional está a possibilidade de se fazer o estudo da história de uma organização, que pode, de acordo com Mendes (2002): comemorar os anos de existência da organização por meio de um resgate de sua memória; para promoção da imagem, buscando fidelizar clientes para auxiliar na tomada de decisão e planejamento estratégico, a médio e longo prazo.

Traduzindo para a realidade dos periódicos científicos, a biografia institucional proporciona fazer um resgate histórico da evolução da publicação científica, apresentando suas dificuldades e conquistas, promovendo a consolidação da publicação como importante difusor científico que atinge critérios de qualidade, relevância e reconhecimento na comunidade científica.

Para chegar aos resultados foram avaliadas todas as edições publicadas da revista e dados do site repositório online da revista. O corpus utilizado para a análise quantitativa foi de 28 volumes publicados

Rev. Diálogo Educ., Curitiba, v. 10, n. 29, p. 123-149, jan./abr. 2010 
do ano 2000 até 2009. O propósito do estudo desdobra-se em atividades que se complementam para o alcance dos resultados:

a) analisar por meio de pesquisa exploratória os editoriais de todas as edições da Revista Diálogo Educacional e, consequentemente, obter sua recuperação histórica;

b) levantar as características formais do periódico no que se refere ao número de artigos publicados;

c) identificar os tipos de autoria (simples ou múltipla), autores mais produtivos (2000-2009), distribuição de artigos por região, frequência dos temas abordados e artigos mais acessados;

d) verificar o comportamento do periódico a partir do momento que foi disponibilizado por meio eletrônico, analisando o alcance de difusão do conhecimento por meio da universalidade.

Para levantar os resultados e realizar a análise dos artigos, foi utilizado o software desenvolvido pelo grupo de pesquisa $\mathrm{E} \mathrm{PI}^{2}$ no qual consiste a metodologia Brapci, que incidi em coletar trabalhos de repositórios científicos pelo protocolo Open Archives Initiative - Protocol for Metadata Harvesting (OAI-PMH) reunindo em uma base de dados os artigos coletados, com identificação de autoria, vínculo institucional, títulos, resumos e palavras-chave, edições disponíveis e tipos das publicações (artigos, editorial, resenhas etc.). Com os artigos indexados, a metodologia disponibiliza a geração de relatórios quantitativos que servem para a realização das análises.

\section{A experiência da Revista Diálogo Educacional}

Essa parte do artigo apresenta a história dos dez anos da Revista Diálogo Educacional contada a partir da análise de todos os editoriais publicados em seus 28 números, como segue.

Vinculada ao Programa de Pós-Graduação Stricto Sensu em Educação da Pontifícia Universidade Católica do Paraná (PUCPR), a Revista Diálogo Educacional, cujo objetivo é divulgar a produção científica local e de professores de outras universidades, proporcionando a difusão e

\footnotetext{
Grupo de pesquisa Educação, Pesquisa e Perfil Profissional em Informação da Universidade Federal do Paraná (UFPR). Disponível em: <www.e3pi.ufpr.br>.
}

Rev. Diálogo Educ., Curitiba, v. 10, n. 29, p. 123-149, jan./abr. 2010 
a reflexão sobre a temática "educação", em 2000 inaugura seu primeiro fascículo do primeiro volume. Esse número histórico foi lançado sob a responsabilidade do editor-chefe Professor Dr. Jamil Ibrahim Iskandar, com periodicidade semestral até o ano de 2001. A partir de 2002, a periodicidade passa a ser quadrimestral, assim mantendo-se até os dias atuais.

Como inicialmente não existia uma preocupação com a endogenia da revista, dos oito artigos publicados no primeiro número, seis foram elaborados por pesquisadores da própria instituição. Reconhecidamente, os desafios e barreiras existentes para a abertura de um periódico científico até sua consolidação na comunidade científica não favorecem a exogenia, o que muitas vezes compromete a primeira avaliação do periódico.

O segundo número já traz claramente o objetivo do periódico, que é dar maior visibilidade à produção científica de seus professores e alunos e intercambiar com pares do Brasil e do exterior o conhecimento produzido em suas linhas de pesquisa: Teoria e Prática da Educação Superior, Administração da Educação Superior e História e Filosofia da educação nos séculos XIX e XX. Fornece também informações acerca da linha editorial, tais como o respeito à liberdade de pensamento, à pluralidade de ideias e a abertura para a veiculação de produções externas ao programa, privilegiando o intercâmbio e combatendo, desse modo, a endogenia, fenômeno prejudicial à construção de um projeto comprometido com a qualidade acadêmico-científica (ZAINKO, 2000).

Com o objetivo de consolidar o intercâmbio entre instituições, o terceiro número traz novas seções, como a de Documentos com a

intenção de ampliar as possibilidades de discussões e de reflexões que se iniciaram no Seminário Avançado: Fundamentos Epistemológicos da Pesquisa em Educação, compartilhando com nossos leitores alguns dos temas que fundamentaram os debates bastante acalorados dos dias 24 e 25 de maio de 2001. Os textos escolhidos sustentaram epistemologicamente os debates (ZAINKO, 2001a, p. 7).

A seção Relatos de Intercâmbios foi criada a partir da avaliação ocorrida na Reunião Regional de Acompanhamento da Conferência Mundial sobre Educação Superior para América Latina e Caribe, já que a PUCPR faz parte do Comitê Regional, representando o Brasil (ZAINKO, 2001a).

Rev. Diálogo Educ., Curitiba, v. 10, n. 29, p. 123-149, jan./abr. 2010 
A seção Notas Técnicas, segundo Zainko (2001a), não obstante o seu caráter de intercâmbio, ganhou destaque pela qualidade do relato apresentado pelo Professor Marco Antonio Rodrigues Dias e, principalmente, pelos subsídios que apresenta para a política universitária neste início de século XXI.

A revista abriu uma seção Resenhas para introduzir o salutar hábito de divulgação das leituras atuais, possibilitando ao leitor novas óticas de análise e despertando o interesse pelas produções que têm subsidiado as ações, quer de docentes / pesquisadores, quer de discentes / pesquisadores (ZAINKO, 2001a).

O quarto número completa os dois anos de existência da revista e reúne a publicação dos artigos elaborados pelos professores da graduação nos seus grupos de pesquisa, buscando socializar e disseminar conhecimentos, e vem de forma incontestável reafirmar que a universidade avança em qualidade porque associa ensino, pesquisa e extensão (ZAINKO, 2001b). Apresentou artigos voltados à articulação Graduação-Pós-Graduação, com destaque para a formação continuada dos professores por meio da pesquisa científica.

A partir de 2002, com a publicação dos números cinco, seis e sete, a revista passa a ter efetivamente periodicidade quadrimestral e a internacionalização de seu conselho editorial. O quinto número apresenta uma retrospectiva do que foi realizado nos primeiros quatro números da revista, pautado pela consistência das suas contribuições ao debate educacional, pela perspectiva de aperfeiçoamento constante, pela ampliação das possibilidades de intercâmbio e, fundamentalmente, pela sua capacidade de articulação entre áreas, instituições, programas e grupos de pesquisa sustentados por projetos institucionais integrados (ZAINKO, 2002a). Por sua vez, o sexto número traz artigos que buscam contemplar a possibilidade de reflexão sobre temas que se encontram em evidência no debate educacional brasileiro, da América Latina e da Europa (ZAINKO, 2002b), enquanto o sétimo número reafirma a revista como espaço permanente de reflexão interna/externa. Embora a revista tenha corrido e ainda corra o risco de ter a sua proposta confundida com a de uma vocação endógena e local, ela deverá preservar sua marca institucional, continuando a ser aperfeiçoada, sem nunca perder de vista o seu compromisso como instrumento de socialização e de divulgação do pensamento educacional, genuíno e brasileiro (ZAINKO, 2002c).

Rev. Diálogo Educ., Curitiba, v. 10, n. 29, p. 123-149, jan./abr. 2010 
No ano de 2003, a revista passa por uma nova configuração e inicia seu número com espaço para dossiê temático, com a finalidade de propiciar aos leitores nacionais e internacionais o debate acerca de temas de interesse voltados à educação. $O$ número oito abordou o tema "Escola, formação docente, trabalho do professor", enquanto no número nove, "Metodologia, política e filosofia da educação", destaca-se a superação da endogenia natural de que se revestia no início. Alcança a exogenia, contando a partir de então com o Conselho Editorial constituído de pesquisadores da área da educação, do país e do estrangeiro, de renome nacional e internacional, para avalizar a credibilidade na área e a indexação da revista nas bases Bibliografia Brasileira de Educação (BBE), EDUBASE e Red Latinoamericana de Información y Documentación en Educación (REDUC/FCC) (MESQUITA, 2003), assim como no Sistema Regional de Información en Línea para Revistas Científicas de América Latina, el Caribe, España y Portugal (LATINDEX). O número dez discutiu "A didática e a nova cultura de aprendizagem".

Em 2004, o número onze apresentou o dossiê voltado à discussão de "Políticas e gestão da educação superior", nesse número foi resolvido pelo colegiado do Programa de Mestrado em Educação da PUCPR que cada uma das linhas de pesquisa do programa assumisse um número da revista. Neste mesmo ano, o número doze abordou o tema "Educação, comunicação e tecnologia (I)" e o treze "Educação, comunicação e tecnologia (II)".

No ano de 2005, o número quatorze apresenta uma reflexão sobre o tema "Diferentes olhares sobre a História da Educação", o quinze, "Mídia educação: olhares multimidiáticos sobre práticas educacionais" e o dezesseis "Saberes Docentes". Nesse último número a revista assume um novo desafio e já pode contar sua trajetória por meio de seus novos editores-chefe Prof. Dr. Sérgio Rogério Azevedo Junqueira e Profa. Dra. Sônia Cristina Soares Dias Vermelho. O primeiro editor da Revista Diálogo Educacional foi o Prof. Dr. Jamil Ibrahim Iskandar, em seguida assumiu o Prof. Irineu Martim, substituído pela Profa. Dra. Maria Amélia Sabbag Zainko, e o novo editor foi o Prof. Dr. Peri Mesquida. No número 16, além da temática central, houve a possibilidade de publicar artigos diversos. O objetivo da Revista Diálogo Educacional foi reafirmado nesse número, tendo em vista dialogar com a comunidade acadêmica sobre pensar a educação nacional, especialmente sobre a formação de professores (JUNQUEIRA, 2005).

Rev. Diálogo Educ., Curitiba, v. 10, n. 29, p. 123-149, jan./abr. 2010 
Em 2006, a revista consegue atender de maneira plenamente satisfatória aos requisitos de avaliação da CAPES e o número dezessete apresenta a discussão sobre a temática "Políticas e gestão da educação". Nesse número, o editorial volta-se à estrutura de organização da revista, destacando que a responsabilidade das diferentes Linhas de Pesquisa do Programa vem abordando temáticas específicas, norteadoras dos estudos e pesquisas desenvolvidas em cada uma das Linhas. Desse modo, promovem o debate acadêmico de cunho interno, entre os pesquisadores docentes e discentes do Programa e externos, com pesquisadores de todas as universidades brasileiras, acerca dos estudos e pesquisas realizadas (BONETI, 2006). O número dezoito discute a "História da Educação Matemática" e o dezenove, "Pesquisa em educação".

Em 2007, o número vinte trata de "Conexões do processo de aprendizagem e conhecimento", o vinte e um dirige-se à "Reforma Universitária Brasileira" e o vinte e dois enfoca o tema "Complexidade". Nesse último número, a revista apresenta seu site com acesso aberto e gratuito de todos os seus números, desde seu lançamento, com visitação de 6.000 usuários nacionais e internacionais nos seus primeiros três meses de funcionamento. Assim, a responsabilidade, pela qualidade e expressão da Revista Diálogo Educacional, se amplia, pois fica evidente a possibilidade de um intercâmbio entre os educadores do Brasil e do exterior, gerando visibilidade em um veículo de comunicação que acolhe a produção do conhecimento dos educadores que se interessam por diferentes temáticas da Educação" (BEHRENS, 2007).

No ano de 2008, o número vinte e três trata da questão das "Licenciaturas", o vinte e quatro volta-se à "Educação a distância", e o vinte e cinco, à "História da Educação Matemática".

Já em 2009, a revista, em seu número vinte e seis, discute "Pós-Graduação e Pesquisa". Organiza-se por temas específicos vinculados às linhas de pesquisa do programa: Teoria e Prática na Formação de Professores e História e Políticas da Educação. O editorial desse número relata que, em 2007, o Programa de PósGraduação em Educação da PUCPR ampliou suas atividades com o credenciamento do Doutorado, consolidando ainda mais o desenvolvimento da pesquisa na instituição (MARTINS; PINTO, 2009). O número vinte e sete apresenta "História e políticas da educação e a formação de professores" e o vinte e oito refere-se à "Violência na escola", expondo que a PUCPR desenvolve estudos

Rev. Diálogo Educ., Curitiba, v. 10, n. 29, p. 123-149, jan./abr. 2010 
136 BUFREM, L. S.; GABRIEL JUNIOR, R. F.; GONÇALVES, V.

sobre a temática desde 2004, tendo sido oficializado no primeiro semestre de 2007, mediante assinatura de convênio entre a PUCPR e o Observatório de Violências nas Escolas-Brasil - parceria estabelecida entre a Unesco e a Universidade Católica de Brasília. O grupo de pesquisadores do Observatório de Violências nas Escolas PUCPR integra essa rede que agrega pesquisadores de diversas universidades e observatórios no Brasil e no Exterior, vinculado à Cátedra da Unesco, Educação, Juventude, Sociedade (EYNG, 2009).

Finalizada a análise dos editoriais, a história da revista complementa-se pelo desenvolvimento de um software específico para gestão de publicação científica, integrando a política de arquivos abertos com ferramentas de interoperabilidade com outras bases de dados $\left(\mathrm{RE}^{2} \mathrm{Ol}\right)$, no ano 2006. Promove-se, assim, a disponibilização de todas as edições até então publicadas exclusivamente em papel da Revista Diálogo Educacional, desde sua primeira edição no ano 2000, em um repositório mantido para todas as revistas científicas da PUCPR. O acesso aberto ao repositório da revista pode ser feito por meio do site <www.pucpr.br/dialogo>.

Até o ano de 2006 a revista apresentava classificação "C" Nacional na área de avaliação Educação, do Qualis/CAPES. Entretanto, esse cenário foi modificado quando o propósito da revista conquistou sua plenitude, sendo reavaliada em 2007 como B1, contribuindo para a avaliação do Curso de Doutorado e Mestrado em Educação da Instituição, que obteve nota 4 pela CAPES. A preocupação em buscar autores de outras instituições, tanto nacionais quanto internacionais, para consolidação da revista foi um dos fatores que mais contribuíram para a redução da endogenia nos anos de 2006 a 2009. Com a circulação online, de forma integral e gratuita, houve um aporte significativo para uma maior visibilidade da revista e, consequentemente, foram atraídos maior número de pesquisadores que não tinham conhecimento da publicação. Aliado a esses fatores, o incentivo à pesquisa por parte da PUCPR propiciou o desenvolvimento e a produção científica dos membros docentes da instituição (JULIATTO, 2005), possibilitando financeiramente a operacionalização da publicação da Revista Diálogo Educacional. Com a seriedade nos trabalhos e busca de agências de fomento, pela primeira vez na história da PUCPR a revista recebeu recursos para impressão em papel pela Agência de Incentivo à Pesquisa do Paraná, Fundação Araucária, nos anos de 2007 e 2009.

Rev. Diálogo Educ., Curitiba, v. 10, n. 29, p. 123-149, jan./abr. 2010 
O resultado da trajetória da revista pode ser acompanhado quanto ao número de artigos científicos publicados por ano conforme apresentado no Gráfico 1, não fazendo parte deste gráfico os outros tipos de seções que foram publicadas na revista ao longo dos anos. A análise do Gráfico 1 permite afirmar o crescimento no número de artigos publicados a cada ano, passando-se de 20 artigos em 2000 para 40 no final de 2009 , atingindo seu ápice no ano de $2008 \mathrm{com}$ 48 artigos publicados/ano.

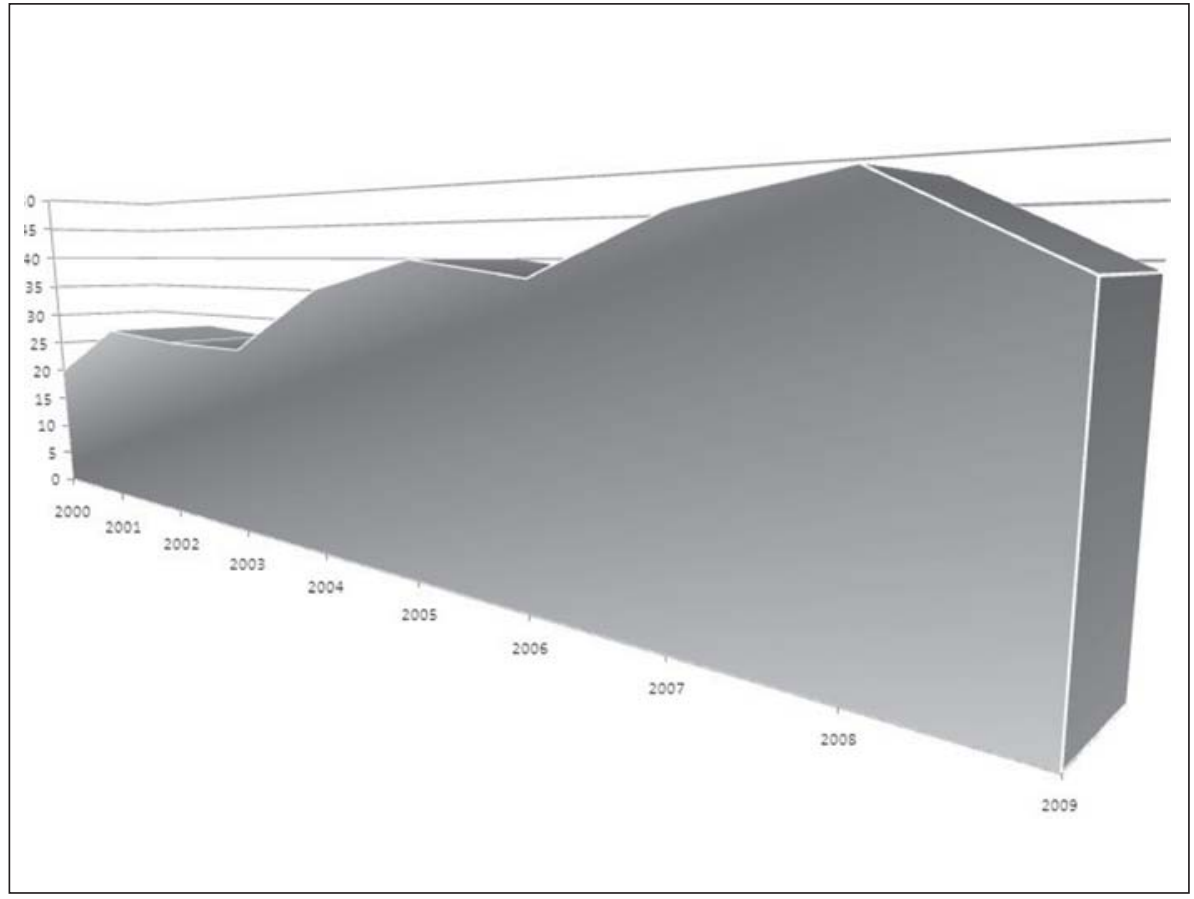

GRÁFICO 1 - Artigos científicos publicados por ano (2000-2009)

Da composição de todas as seções da revista, foram publicados ao todo 414 trabalhos, destes, os artigos científicos representam $84,0 \%$, ou seja, (347 artigos), em seguida os editoriais representam $6,8 \%$ (num total de 28), as resenhas 4,9\% (correspondendo a 21), os documentos e comunicações $3,9 \%$ (representados por 16) e recensão e entrevista $0,4 \%$ (com total de 2 publicações).

Rev. Diálogo Educ., Curitiba, v. 10, n. 29, p. 123-149, jan./abr. 2010 
BUFREM, L. S.; GABRIEL JUNIOR, R. F.; GONÇALVES, V.

Em relação ao tipo de autoria dos artigos científicos, a grande concentração está na autoria individual e na dupla autoria, conforme demonstrado no Gráfico 2.

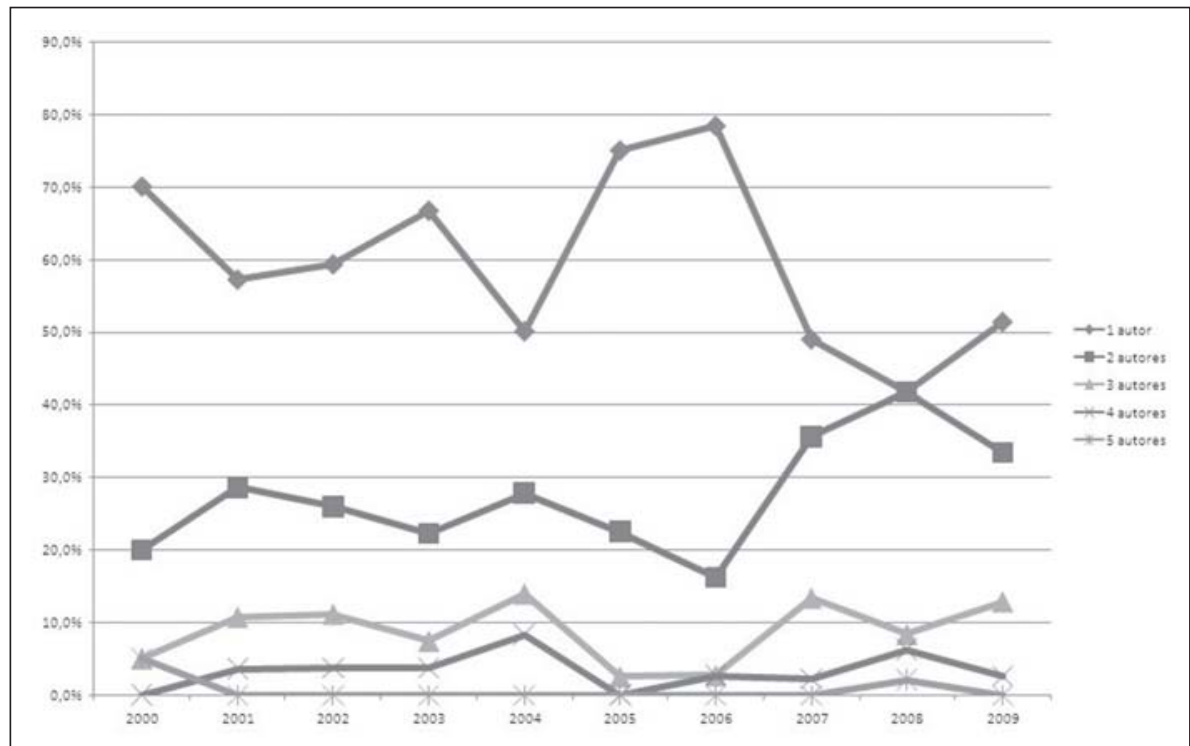

\begin{tabular}{lc}
\hline Número de autores & Total de artigos \\
\hline Autoria única & 203 \\
Dois autores & 99 \\
Três autores & 31 \\
Quatro autores & 12 \\
Cinco autores & 2 \\
\hline
\end{tabular}

GRÁFICO 2 - Tipos de autoria dos artigos

Em estudo retrospectivo sobre tipos de autoria, Bufrem, Arboit e Freitas (2009) observam a tendência à participação de mais de um autor em trabalhos científicos, citando pesquisas como a de Campos e Carvalho (1981), sobre a produção bibliográfica dos professores da Escola de Veterinária da UFMG, no período de 1973 a 1977, em artigos de

Rev. Diálogo Educ., Curitiba, v. 10, n. 29, p. 123-149, jan./abr. 2010 
periódicos, dissertações, teses, monografias e trabalhos apresentados em eventos. Foram analisados 202 artigos de periódicos publicados no período citado, tendo a autoria múltipla alcançado $96 \%$ da produção total, com maior incidência de artigos de quatro autores. Embora o período analisado situe-se na década de 1970 e a predominância de autoria múltipla, de acordo com outras análises, só viesse a ocorrer em períodos mais recentes, pode-se considerar este fenômeno como indicativo de uma tendência em área específica do conhecimento.

Enfocando a produção científica em tecnologia de alimentos realizada na Coletânea do Ital no período de 1990 a 1994, Camargo (1997) confirmou os resultados obtidos por Campos e Carvalho (1981) quando identificou grande maioria de autoria múltipla $(98,68 \%)$ na análise dos artigos científicos, constatando somente um artigo de autoria única no ano de 1991. A análise revelou ainda a predominância de artigos sob responsabilidade de quatro autores, o mesmo ocorrendo em relação aos artigos de revisão, entre os quais 55\% são de autoria múltipla ou coletiva e $41 \%$, de autoria única.

Nascimento (1983), Octaviano (1991), Andrade (1984) e Santos (1997) também constataram o padrão de autoria múltipla em suas pesquisas.

A crescente preferência pela produção de artigos em colaboração pode representar uma tendência já verificada na literatura mundial, a de estar a ciência cada vez mais sendo desenvolvida em equipe. Esse fenômeno explica-se principalmente pelas possibilidades de intercâmbios interdepartamentais e interinstitucionais, cuja intensificação tem sido ampliada proporcionalmente aos sucessos das tecnologias na área de comunicação. Targino e Caldeira (1988) confirmam essa tendência no estudo em que observam o predomínio da autoria múltipla concretizada pelo inter-relacionamento dos professores da Faculdade estudada com os professores de outras unidades da própria universidade ou de outras instituições.

Como resultado da análise de autoria, relativamente ao modo de produção, estudo de caráter analítico-descritivo sobre as relações interinstitucionais e de autoria em 4.961 artigos das 28 revistas indexadas na Brapci, no período de 1970 a 2007, Bufrem, Arboit e Freitas (2009) constatam a predominância de trabalhos individuais, em percentual de $68,1 \%$ do universo de artigos, enquanto que $31,9 \%$ são de autoria múltipla, observando como índice de coautoria o resultado de 1,6 autor por documento. A cifra de trabalhos

Rev. Diálogo Educ., Curitiba, v. 10, n. 29, p. 123-149, jan./abr. 2010 
140 BUFREM, L. S.; GABRIEL JUNIOR, R. F.; GONÇALVES, V.

individuais traz à tona uma representação divergente das pesquisas citadas, como a de Nascimento (1983), Octaviano (1991), Andrade (1984) e Santos (1997), que constataram o predomínio do padrão de autoria múltipla em suas pesquisas. Entretanto, deve-se observar que o estudo retrospectivo das autoras adquire abrangência ampla, incorporando ao corpus artigos da década de 1970, o que, no conjunto dos artigos históricos, vai contribuir para um comportamento médio influenciado pelas práticas mais remotas.

A pesquisa de Vilan Filho (2009) coincide com os resultados anteriores, demonstrando que a maior parte dos artigos publicados entre 1972 e 2007, nos periódicos científicos brasileiros das áreas de informação, é de autoria única, quase $71 \%$ do total. O autor destaca também que apesar da produção anual de artigos em autoria única ser maior do que a produção de artigos em autoria múltipla durante todo o período estudado, a diferença entre a produção dos artigos em autoria única e múltipla diminuiu bastante nos últimos anos. Por outro lado, este estudo sobre a Revista Diálogo Educacional revela um decréscimo na tendência de dupla autoria a partir de 2009, redução que pode estar relacionada com a nova estratificação da CAPES, obtida em 2007, provocando interesse dos autores em publicar na revista. ${ }^{3} \mathrm{O}$ aumento das submissões também pode ser comprovado, no Quadro 2, pela redução da endogenia do periódico nos anos de 2008 e 2009 , período que apresentou as mais baixas taxas de publicação local $(22,9 \%$ e $22,5 \%)$.

QUADRO 2 - Distribuição de artigos por regionalidade

\begin{tabular}{lclll}
\hline Ano & Internacional & Nacional & Local & Total \\
\hline 2009 & $6(15,0 \%)$ & $25(62,5 \%)$ & $9(22,5 \%)$ & 40 \\
2008 & $8(16,7 \%)$ & $29(60,4 \%)$ & $11(22,9 \%)$ & 48 \\
2007 & $5(11,1 \%)$ & $28(62,2 \%)$ & $12(26,7 \%)$ & 45 \\
2006 & $5(13,2 \%)$ & $21(55,2 \%)$ & $12(31,6 \%)$ & 38 \\
\hline
\end{tabular}

O fato foi observado pelo aumento significativo no número de artigos submetidos para análise da revista.

Rev. Diálogo Educ., Curitiba, v. 10, n. 29, p. 123-149, jan./abr. 2010 
Dos autores mais produtivos individualmente ou em autoria múltipla nesses dez anos destacam-se: Sérgio Rogério Azevedo Junqueira (PUCPR) e Maria Amélia Sabbag Zainko (PUCPR), com dez artigos; Neuza Bertoni Pinto (PUCPR) e Maria Lourdes Gisi (PUCPR), com nove artigos; Peri Mesquida (PUCPR), com sete artigos; Paulo Roberto Alcântara (PUCPR), Lilian Anna Wachowicz (PUCPR) e Marilda Aparecida Behrens (PUCPR), com seis artigos. $\mathrm{O}$ vínculo institucional dos autores está ligado diretamente à instituição mantenedora do periódico no programa de Pós-Graduação em Educação da PUCPR e demonstra que os autores utilizam a revista para divulgar seus resultados de pesquisa, abrindo o debate acerca da temática em estudo com pesquisadores de outras instituições, cujas áreas de interesse coincidam; desse modo, o resultado apresentado não afeta nem compromete o critério de limitação de publicação local perante a estratificação da CAPES.

Confirma-se desse modo a influência dos órgãos de fomento nos modos de produção da literatura científica, facilitando a compreensão das relações que se ampliam, conforme analisa Bufrem (2009):

As configurações de autoria e de relações relevantes destacam a forte influência dos trabalhos de grupos de pesquisas, anunciando tendências como a ampliação da autoria múltipla e tornando mais visíveis as relações interinstitucionais presentes nessa área de produção científica. Esse fenômeno é influenciado pelas políticas de fomento às pesquisas interinstitucionais, por um lado e, por outro, à fragilidade dos limites definidores de domínios científicos.

Essa influência revela-se também nas colaborações e relacionamentos interinstitucionais, contribuindo para a configuração das redes sociais e para a compreensão das relações endógenas e exógenas, cujos resultados se expressam igualmente na avaliação institucional.

No que se refere à análise de conteúdo, o Quadro 3 apresenta os descritores, ou seja, a incidência dos assuntos mais discutidos na revista, utilizando-se as palavras-chave. Pode-se observar que correspondem ao propósito da revista, que é o de publicar originais de pesquisas destinados à área de educação na forma de artigos científicos

Rev. Diálogo Educ., Curitiba, v. 10, n. 29, p. 123-149, jan./abr. 2010 
142 BUFREM, L. S.; GABRIEL JUNIOR, R. F.; GONÇALVES, V.

e resenhas direcionados a profissionais afins (NORMAS..., 2009). A maior quantidade de artigos concentra-se nas áreas de Educação (geral), Formação de professores, História e Aprendizagem.

Por se utilizar de uma seleção temática em cada uma de suas edições, a Revista Diálogo Educacional convida especialistas das áreas a nortearem as discussões por meio da publicação, contribuindo para a concentração no foco da revista.

QUADRO 3 - Frequência de temas abordados

\begin{tabular}{lclc}
\hline Descritor & Incidência & Descritor & Incidência \\
\hline Educação & 35 & Complexidade & 5 \\
Formação de professores & 13 & Exclusão & 5 \\
História & 12 & Aprendizagem & 5 \\
& & colaborativa & \\
Aprendizagem & 11 & Prática pedagógica & 5 \\
Educação Superior & 9 & Avaliação & 5 \\
Educação a distância & 8 & Saberes & 5 \\
Conhecimento & 7 & Violência & 5 \\
Ética & 7 & Formação docente & 5 \\
Ensino religioso & 6 & Metodologia & 5 \\
Movimento da matemática & 6 & Matemática & 5 \\
moderna & & & 5 \\
Ensino & 6 & Escola & \\
\hline
\end{tabular}

Com a publicação online do conteúdo na íntegra dos seus artigos, a Revista Diálogo Educacional ganhou visibilidade, tanto nacional quanto internacional, sendo indexada pelos principais mecanismos de buscas mundiais. O sistema de repositório permitiu a identificação da origem do acesso, ou a indicação do mecanismo que submeteu o navegador para acesso à revista, estes mecanismos encontram-se descritos no Quadro 4 e apontam que o Google é o principal mecanismo que direciona ao conteúdo da revista.

Rev. Diálogo Educ., Curitiba, v. 10, n. 29, p. 123-149, jan./abr. 2010 
Dez anos de Revista Diálogo Educacional (2000-2009)

QUADRO 4 - Origens de acesso remoto

\begin{tabular}{lr}
\hline Origem & Total de indicação \\
\hline www.google.com.br & 268.159 \\
www.google.com & 15.661 \\
www.google.pt & 10.144 \\
www.pucpr.br & 9.613 \\
www.biblioteca.pucpr.br & 2.737 \\
www.busca.uol.com.br & $871 *$ \\
search.live.com & 1.238 \\
buscador.terra.com.br & 1.214 \\
search.conduit.com & 1.143 \\
www.google.es & 1.072 \\
www.google.com.mx & 1.016 \\
www.bing.com & 970 \\
www.google.com.co & 828 \\
www.periodicos.capes.gov.br & 871 \\
www.google.co.ve & 745 \\
\hline
\end{tabular}

* buscado www.mundo.buscador.com.br

A quantidade de acesso ao site da revista vem crescendo desde sua disponibilização online, de 58.615 downloads de artigo completo em PDF em 2007 para 107.191 downloads em 2009. Os acessos aos resumos passaram de 19.347 em 2007 para 39.101 em 2009. A quantidade maior de acesso ao PDF ocorre pelo motivo dos mecanismos de buscas direcionarem para o artigo, sem muitas vezes nem acessarem o resumo do artigo na revista. O crescimento de acesso aos artigos da revista está representado no Gráfico 3.

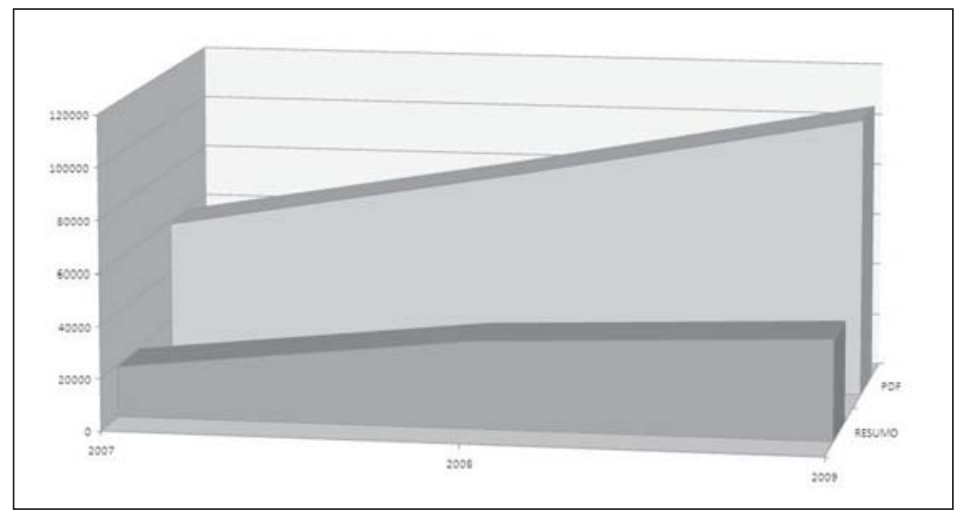

GRÁFICO 3 - Download e acesso ao site da Revista Diálogo Educacional (2007-2009)

Rev. Diálogo Educ., Curitiba, v. 10, n. 29, p. 123-149, jan./abr. 2010 
Os resultados demonstram a evolução do processo editorial da Revista Diálogo Educacional como um todo e apontam que, a partir do momento em que a revista passa a ter disponibilização online, seu alcance permite maior visibilidade e consagração.

Dos artigos mais acessados online destacam-se: Souza Filho (2008) com o artigo Relações entre aprendizagem e desenvolvimento em Piaget e em Vygotsky: dicotonomia ou compatibilidade? possuindo o total de 17.405 downloads; em seguida Iskandar e Leal (2002) Sobre positivismo e educação com 5.039 downloads e por fim, Pascoal (2007) O pedagogo na empresa com 4.332 downloads.

Até o ano de 2007, a Revista Diálogo Educacional possuía tiragem de 1.000 exemplares para cada número publicado, porém mediante os resultados obtidos pela publicação online, esse número passou para 600 a partir do ano de 2008, sendo que destes, 209 exemplares são destinados à permuta com instituições públicas e particulares do Brasil e do exterior e o restante atende a uma pequena cota de assinaturas e distribuição gratuita.

\section{CONSIDERAÇÕES FINAIS}

A aplicação da técnica de biografia institucional, em conjunto com a coleta de dados utilizando o site da revista e o software de análise da metodologia Brapci, possibilitou a recuperação histórica da Revista Diálogo Educacional, atingindo-se o objetivo principal deste trabalho.

Por meio de uma pesquisa exploratória nos editoriais, foi possível suprir as necessidades informacionais que serviram a pesquisa e sua recuperação histórica. A aplicação da metodologia Brapci proporcionou um levantamento da quantidade de edições por ano e por tipo de publicação (artigo, resenha), bem como a quantidade de autores e sua afiliação institucional, possibilitando, assim, a identificação da região dos autores por artigo publicado.

Utilizando-se o próprio relatório disponibilizado pelo $\mathrm{RE}^{2} \mathrm{Ol}$ (software mantenedor da revista), foi possível recuperar os dados de acesso às revistas e aos artigos mais consultados no período de 2007 a 2009.

Diante do que foi exposto, é possível considerar que a Revista Diálogo Educacional ao longo dos anos conseguiu cumprir sua proposta

Rev. Diálogo Educ., Curitiba, v. 10, n. 29, p. 123-149, jan./abr. 2010 
inicial, conquistando seu espaço num ambiente constituído por 1.162 revistas científicas avaliadas pela $\mathrm{CAPES}^{4}$, em 2007, na área de Educação, sendo que, nesse universo, 120 revistas, cerca de $10 \%$ de todas as publicações, apresentam avaliação B1, e ainda deste total 50 revistas, cerca de $40 \%$, são internacionais.

Esses resultados apontam que a revista se encontra no caminho para seu reconhecimento internacional e o pensamento e a ação de seus idealizadores, juntamente com o apoio da Universidade, asseguram sua criação e permanência como veículo de comunicação científica.

Desde o seu início, a revista vislumbrava a difusão do discurso pensado acerca da temática educação com objetivo de alcance nacional e internacional aos poucos sendo conquistado perante a comunidade, o que se torna mais evidente a partir do ano de 2006, quando cerca de $80 \%$ de todos os artigos publicados foram de outras instituições e a revista passou a ser disponibilizada online gratuitamente.

O auxílio de recursos tecnológicos, aliados a manifestações de autores, leitores, pareceristas, colaboradores, instituições e organizações, foi fundamental para sua visibilidade, uma vez que por meio deles foi divulgada de maneira mais ampla a revista em páginas pessoais e sites.

O ano de 2010 inicia com a meta de a revista ser indexada pelo Red de Revistas Científicas de América Latina y el Caribe, España y Portugal - Sistema de Información Científica Redalyc. A revista atende a todos os itens de avaliação para indexação e espera com isso avançar para o estrato A2.

Com este estudo, se buscou apresentar como foi conduzida a Revista Diálogo Educacional nos seus primeiros dez anos e mostrar seus desafios e conquistas. Por meio do aprendizado acumulado, buscando traçar estratégias que garantam velocidade, visibilidade e reconhecimento, sem perda de qualidade, espera-se que, em estudos futuros já tenham sido concretizados os propósitos que atualmente impulsionam seu planejamento.

\footnotetext{
Disponível em: <qualis.capes.gov.br/webqualis/ConsultaListaCompletaPeriodicos.faces>. Acesso em: 28 dez. 2009.
}

Rev. Diálogo Educ., Curitiba, v. 10, n. 29, p. 123-149, jan./abr. 2010 
146 BUFREM, L. S.; GABRIEL JUNIOR, R. F.; GONÇALVES, V.

\section{REFERÊNCIAS}

ANDRADE, M. T. D. de. Literatura citada em dissertações e teses no campo da epidemiologia, apresentadas à Faculdade de Saúde Pública da Universidade de São Paulo, no período de 1979-1982. 1984. 95 f. Dissertação (Mestrado em Saúde Pública) - Universidade de São Paulo, São Paulo, 1984.

BEHRENS, M. A. Editorial. Revista Diálogo Educacional, Curitiba, v. 7, n. 22, p. 7, set./dez. 2007.

BOARINI, M. L. A universidade e o editor científico. Revista Espaço Acadêmico, Maringá, PR, v. 29, 2003. Disponível em: <www.espacoacademico.com.br/029/ 29cboarini.htm>. Acesso em: 30 set. 2008.

BONETI, L. W. Editorial. Revista Diálogo Educacional, Curitiba, v. 6, n. 17, p. 7, jan./abr. 2006.

BOURDIEU, P. A economia das trocas simbólicas. São Paulo: Perspectiva, 1987.

BUFREM, L. S. Relações interinstitucionais e autoria em artigos de revistas científicas de ciência da informação no Brasil. In: ENCONTRO NACIONAL DE PESQUISA EM CIÊNCIA DA INFORMAÇÃO, 10., 2009, João Pessoa. Anais... João Pessoa: XANCIB/PPGCI UFPb, 2009.

BUFREM, L. S.; ARBOIT, A.; FREITAS, J. Configuração epistemológica da Ciência da Informação na literatura periódica brasileira: análise de contexto teórico (1970-2008). EDIBCIC, Brasil, jun. 2009. Disponível em: <eventos-iuc.com/ ocs/index.php/edibcic2009/EDIBCIC/paper/view/113>. Acesso em: 28 out. 2009.

CAMArgo, M. V. G. P. de. Produção científica em tecnologia de alimentos: artigos da coletânea do ITAL (1990/1994). 1997. 136 f. Dissertação (Mestrado em Biblioteconomia) - Pontifícia Universidade Católica de Campinas, Campinas, 1997.

CAMPOS, C. M.; CARVALHO, M. M. de. Análise da produção bibliográfica dos professores da Escola de Veterinária da UFMG, no período de 1973 a 1977. Revista da Escola de Biblioteconomia, Belo Horizonte, v. 10, n. 2, p. 208-225, set. 1981.

Rev. Diálogo Educ., Curitiba, v. 10, n. 29, p. 123-149, jan./abr. 2010 
CASTRO, R. C. F. Indicadores de avaliação das revistas científicas nacionais. Fórum Permanente de Conhecimento \& Tecnologia da Informação. Campinas, 8 mar. 2008. Disponível em: <www.cori.unicamp.br/foruns/tecno/evento21/ regina.ppt>. Acesso em: 28 out. 2009.

COORDENAÇÃO DE APERFEIÇOAMENTO DE PESSOAL DE NÍVEL SUPERIOR - CAPES. Disponível em: <www.capes.gov.br>. Acesso em: 28 out. 2009.

EYNG, A. M. Editorial. Revista Diálogo Educacional, Curitiba, v. 9, n. 28, p. 409, set./dez. 2009.

GONÇALVES, A.; RAMOS, L. M. S. V. C.; CASTRO, R. C. F. Revistas científicas: características e critérios de qualidade. In: POBLACION, D. A.; WITTER, G. P.; SILVA, J. F. M. da (Org.). Comunicação \& produção científica: contexto, indicadores e avaliação. São Paulo: Angellara, 2006. p. 163-190.

ISKANDAR, J. I.; LEAL, M. R. Sobre positivismo e educação. Revista Diálogo Educacional, Curitiba, v. 3, n. 7, p. 89-94, set./dez. 2002.

JULIATTO, C. I. (Coord.). Um jeito próprio de investigar: a produção do conhecimento pela pesquisa. Curitiba: Champagnat, 2005.

JUNQUEIRA, S. R. A. Editorial. Revista Diálogo Educacional, Curitiba, v. 5 , n. 16 , p. 7 , set./dez. 2005.

KRZYZANOWSKI, R. F.; FERREIRA, M. C. G. Avaliação de periódicos científicos e técnicos brasileiros. Ciência da Informação, Brasília, v. 27, n. 2, p. 165-175, maio/ago. 1998.

MARTINS, P. L. O.; PINTO, N. B. Editorial. Revista Diálogo Educacional, Curitiba, v. 9, n. 26, p. 7, jan./abr. 2009.

MEADOWS, A. J. A comunicação científica. Brasília: Briquet de Lemos, 1999.

MENDES, J. A. Problemas de história empresarial: teoria e prática. ENCONTRO ASSOCIAÇ̃̃O PORTUGUESA DE HISTÓRIA ECONÔMICA E SOCIAL, 22, 2002. Anais... Aveiro, 2002. Disponível em: <www2.egi.ua.pt/xxiiaphes/ Artigos/a\%20JA\%20Mendes.PDF>. Acesso em: 28 out. 2009.

MESQUITA, P. Editorial. Revista Diálogo Educacional, Curitiba, v. 4, n. 8, p. 7 , jan./abr. 2003.

Rev. Diálogo Educ., Curitiba, v. 10, n. 29, p. 123-149, jan./abr. 2010 
NASCIMENTO, M. de J. Estudo da produção científica na área nuclear no período de 1970/1979. 1983. 206 f. Dissertação (Mestrado em Ciência da Informação) - Universidade Federal do Rio de Janeiro/IBICT, Rio de Janeiro, 1983.

NORMAS para publicação. In: REVISTA DIÁLOGO EDUCACIONAL. Curitiba: Champagnat, 2009.

OCTAVIANO, V. L. C. Instrumentação agropecuária brasileira: sistematização da informação e documentação produzida pelos pesquisadores da EMBRAPA/ NPDIA, 1977/1989. 1991. 131 f. Dissertação (Mestrado em Biblioteconomia) Pontifícia Universidade Católica de Campinas, Campinas, 1991.

PASCOAL, M. O pedagogo na empresa. Revista Diálogo Educacional, Curitiba, v. 7, n. 22, p. 183-193, set./dez. 2007.

PRICE, D. de S. A ciência desde a Babilônia. Belo Horizonte: Itatiaia; São Paulo: EDUSP, 1976.

SANTOS, M. C. L. dos. Produção científica: análise do periódico Química Nova (1991-1995). In: WITTER, G. P. (Org.). Produção científica. Campinas: Átomo, 1997. p. 65-76.

SOUZA FILHO, Marcilio Lira de. Relações entre aprendizagem e desenvolvimento em Piaget e em Vygotsky: dicotonomia ou compatibilidade? Revista Diálogo Educacional, Curitiba, v. 8, n. 23, p. 265-275, jan./abr. 2008.

STUMPF, I. R. C. Avaliação das revistas de comunicação pela comunidade acadêmica da área. Em Questão, Porto Alegre, v. 9, n. 1, p. 25-38, jan./jun. 2003.

TARAPANOFF, K. Técnicas para tomada de decisão nos sistemas de informação. Brasília: Thesaurus, 1995.

TARGINO, M. das G.; CALDEIRA, P. da T. Análise da produção cientifica em uma instituição de ensino superior: o caso da Universidade Federal do Piauí. Ciência da Informação, Brasília, v. 17, n. 1, p. 15-25, jan./jun. 1988.

VILAN FILHO, J. L. Periódicos científicos nas áreas de informação no Brasil: produção de artigos em colaboração e o gênero dos autores. In: ENCONTRO NACIONAL DE PESQUISA EM CIÊNCIA DA INFORMAÇÃO, 10., 2009, João Pessoa. Anais... João Pessoa: XANCIB/PPGCI UFPb, 2009.

ZAINKO, M. A. S. Editorial. Revista Diálogo Educacional, Curitiba, v. 1, n. 2, p. 7, jul./dez. 2000 .

Rev. Diálogo Educ., Curitiba, v. 10, n. 29, p. 123-149, jan./abr. 2010 

jun. 2001a.

Editorial. Revista Diálogo Educacional, Curitiba, v. 2, n. 3, p. 7, jan./

Editorial. Revista Diálogo Educacional, Curitiba, v. 2, n. 4, p. 7, jul./ dez. 2001b.

Editorial. Revista Diálogo Educacional, Curitiba, v. 3, n. 5, p. 7, jan./ abr. 2002a.

Editorial. Revista Diálogo Educacional, Curitiba, v. 3, n. 6, p. 7, maio/ ago. 2002b. dez. 2002c.

Editorial. Revista Diálogo Educacional, Curitiba, v. 3, n. 7, p. 7, set./

Recebido: 30/11/2009

Received: 11/30/2009

Aprovado: 05/01/2010

Approved: 01/05/2010

Rev. Diálogo Educ., Curitiba, v. 10, n. 29, p. 123-149, jan./abr. 2010 